\title{
VERDADE COMO DESVELAMENTO NA FILOSOFIA DE MARTIN HEIDEGGER
}

Truth as unconcealment in Martin Heidegger's philosophy

Ana Carla de Abreu Siqueira*

Resumo: O objetivo deste trabalho é discutir a questão da verdade, que se define como um dos momentos mais importantes da filosofia de Martin Heidegger. Em primeiro lugar, isto se dá abordando o conceito de verdade em Ser $e$ Tempo (1927), focando especificamente na visão estabelecida no parágrafo 44 . Em seguida, tentamos fornecer uma análise da questão da verdade como correção pra questão do desvelamento, o qual ele entende como um evento que retira os entes do velamento. Heidegger alcançou uma noção de verdade não mais a partir de sentenças ou do Dasein, mas sim da ideia de que existem verdade e nãoverdade. Sempre há algo que permanece escondido. Neste sentido, podemos explorar algumas considerações na sua obra tardia e falar do fundamento da noção de verdade.

Palavras-chave: Verdade. Dasein.

\begin{abstract}
The aim of this paper is to discuss the question of truth, which is one of the most important moments in Martin Heidegger's philosophy. It proceeds, first of all, addressing the concept of truth in Being and Time (1927), specifically focus on the view he establishes in section 44 . Then we aim to provide an analysis from the question of truth as correctness to the question of unconcealment, which he understands as an event that removes entities from the concealment. Heidegger achieved a notion of truth not anymore by the assertions or Dasein, but rather by the concept that there's truth and untruth. There is always something that remains hidden. In this sense, we can explore some considerations on his later work and talk about the ground of the notion of truth.
\end{abstract} Keywords: Truth. Dasein. Unconcealment. Desvelamento.

* Mestre em Filosofia pela Universidade Federal do Ceará (UFC). Bolsista CAPES. Contato: carladeabreus@gmail.com 


\section{Introdução}

O tema da verdade situa-se em destaque no pensamento heideggeriano. Sua crítica ao conceito tradicional de verdade, o qual a definia como adequação (adequatio), não aparece como um conteúdo arbitrário. Ao contrário, essa discussão possui fundamentos sólidos na tradição, o que é possível notar através de uma leitura da história da filosofia: tal problemática fora interpretada, a partir dos gregos, como uma questão essencial e indissociável dos demais temas contemplados pelos filósofos. No presente estudo, o que nos importa é a desvinculação deste conceito da sólida ideia de concordância, explanando o modo como nosso autor é conduzido ao desvelamento.

Martin Heidegger (1889-1976) acreditava que a maior dificuldade em alcançar o sentido da aletheia teria sido resultante de uma distância entre os homens de seu tempo (e, por que não, do nosso tempo?) e o momento vivenciado pelos gregos ${ }^{1}$, explorado pelo filósofo alemão com a interpretação sobre a deusa da verdade ${ }^{2}$. Mas justamente essa associação teria colaborado para que a verdade se tornasse uma afirmação irrefutável: sua personificação em uma figura divina e superior, à qual deveríamos nos curvar, evitou que esta questão fosse levantada de maneira apropriada, já que não permitiria que os pensadores entendessem que há algo encoberto.

A questão da verdade foi então retomada sob outra perspectiva, a qual pressupõe pensá-la a partir de uma nova concepção e de relações diferentes das evocadas pelas investigações filosóficas até então vigentes. Por esse motivo, nossa primeira apreensão será em torno do parágrafo 44 de Ser e Tempo, intitulado "Dasein, abertura e verdade", esclarecendo o alcance das análises feitas por seu autor nos parágrafos precedentes a este. Ao entrar em conflito com as teorias fundamentadas na relação sujeito-objeto, o filósofo alemão deixa de falar na consciência ${ }^{3}$ para explicitar o Dasein como abertura.

\section{0 conceito de verdade no parágrafo 44 de Ser e Tempo}

\footnotetext{
${ }^{1}$ Cf. HEIDEGGER, M. Meditação. Tradução de Marco Antônio Casanova. Petrópolis: Vozes, 2010, p102: "ainda não vislumbramos minimamente em sua inicialidade, desprovidos como estamos do distanciamento histórico adequado."

${ }^{2}$ Cf. HEIDEGGER, M. Parmênides. Tradução de Sérgio Mário Wrublevski. Petrópolis: Vozes; Bragança Paulista: Editora Universitária São Francisco, 2008, p.18: “O pensador Parmênides fala de uma deusa que o saúda, depois que ele chegou de sua viagem à casa da deusa. À saudação, cuja essência própria a deusa mesma explicita, ela acrescenta um anúncio das revelações que o pensador deve experimentar no seu caminho através dela. [...] A deusa é a deusa 'Verdade'. Ela mesma - 'a verdade' - é a deusa. Por isso, devemos evitar o modo de falar que falaria de uma deusa 'da' verdade. Pois o modo de falar de uma 'deusa da verdade' desperta a representação de uma deusa a cuja proteção e bênção 'a verdade' é tão-somente confiada. Se fosse o caso, teríamos dois fatos: 'uma deusa' e 'a verdade', que está sob proteção divina.”

${ }^{3}$ Segundo a interpretação de Ernst Tugendhat, o termo consciência remete ao conceito de objeto. Heidegger pretende tirar a referência aos objetos, pois o mundo estaria mais de acordo com uma conexão de sentidos do que com uma totalidade de objetos. (Cf. TUGENDHAT, E. Lições Introdutórias à Filosofia Analítica da Linguagem. Tradução de Ronai Pires da Rocha. Ijuí: Editora Unijuí, 2006)
} 
O conceito de abertura (Erschlossenheit) aparece como um dos existenciais fundamentais do Dasein e essa palavra pode, segundo Ernildo Stein, ser traduzida por "revelação, no sentido de erschliessen, revelar, explorar [...] a condição de aperibilidade, de se poder abrir algo"4. A discussão sobre a verdade é direcionada à abertura do homem e às suas experiências, destituindo o termo das propriedades semânticas assim como do privilégio da correspondência entre sentença e objeto. Além disso, esse conceito mostra que o homem não pode ser caracterizado como fonte de uma certeza incontestável.

A análise prévia feita em torno das dimensões originárias da abertura - disposição afetiva, compreensão e discurso ${ }^{5}$ - conduziu Heidegger à colocação e ao desenvolvimento da questão da verdade. Ele parte do seu conceito tradicional e de sua determinação originária para chegar ao seu caráter derivado, lançando a problemática sobre o modo em que se dá aos homens. Somente após desconstruir os pressupostos sobre os quais nosso entendimento sobre o tema estava apoiado torna-se admissível não pensar a verdade como adequação, mas desvelamento (Unverborgenheit), resgatando o sentido de aletheia $^{6}$. Para rever a investigação promovida pelo pensador, adotamos como ponto de partida a seguinte afirmação:

Três teses caracterizam a concepção tradicional da essência da verdade e a opinião vigente acerca de sua primeira definição: 1 . O "lugar" da verdade é o enunciado (o juízo). 2. A essência da verdade consiste na "concordância" do juízo com seu objeto. 3. Aristóteles, o pai da lógica atribuiu ao juízo o lugar originário da verdade, como também colocou a definição da verdade como "concordância" em curso. ${ }^{7}$

Não se deve dispensar o fato de que juízos e enunciados podem ter o caráter de 'verdadeiro' ou 'falso'. Trata-se aqui de uma atividade filosófica, que não pode ser levada adiante sem a

\footnotetext{
${ }^{4}$ STEIN, E. Pensar e Errar. Um ajuste com Heidegger. Ijuí: Unijuí, 2011, p.21.

5 Heidegger emprega o termo disposição afetiva (Befindlichkeit) para expressar o estado de ânimo no qual Dasein se encontra. Os estados de ânimo escapam de um conhecimento puramente teórico, sobre o qual se situam as análises científicas. São os humores que revelam o estar-lançado (Geworfenheit) no mundo e remetem o homem ao seu mundo histórico, afetivo e prático, sintonizando-o para que as coisas o afetem e despertem seu interesse. Os humores cotidianos fazem o homem aberto a si mesmo e consciente do mundo, dos outros entes e das coisas, fazendo com que ocorra um envolvimento, permitindo que ele reflita sobre suas vivências. O que também já se encontra afetivamente disposta é a compreensão (Verstehen). A cada comportamento, o homem já traz em si uma compreensão prévia do mundo e do que ele próprio é. Dasein é transcendência: compreender permite se projetar em diversas possibilidades e relações. A compreensão prévia se liberta de uma orientação do homem aos objetos, se efetivando na interpretação (Auslegung), quer dizer, a articulação do que fora previamente compreendido. O discurso (Rede) é posterior e consiste em uma atividade essencialmente humana. Por conviver e ligar-se aos outros, o homem possui uma compreensão em comum e, através da fala, compartilha suas opiniões, experiências e ações. A linguagem não é objeto, mas “[...] a linguagem é a casa do Ser, edificada em sua propriedade pelo Ser e disposta a partir do Ser.” (Cf. INWOOD, M. Dicionário Heidegger. Tradução de Luísa Buarque de Holanda. Rio de Janeiro: Jorge Zahar Editor, 2002, p.55) A linguagem mediatiza toda a experiência do mundo porque é um acontecimento, não um instrumento e carrega a função de descobrir ou tirar da ocultação, articulando aquilo que ser-no-mundo compreende em suas convivências e seu agir cotidiano.

${ }^{6}$ Cf. HEIDEGGER, M. Aletheia (Heráclito, fragmento 16). In: Ensaios e Conferências. Coleção Pensamento Humano. $7^{a}$ edição. Tradução de Márcia Sá Cavalcante Schuback. Petrópolis: Vozes; Bragança Paulista: Editora Universitária São Francisco, 2006, p.229: “o traço fundamental daquilo que já apareceu e que deixou para trás o encobrimento. Esse é o sentido do alfa $(\alpha)$ que compõe a palavra grega aletheia e que somente recebeu a designação de alfa privativo na gramática elaborada pelo pensamento grego tardio".

${ }^{7}$ HEIDEGGER, M. Ser y Tiempo. Coleção: El saber y la Cultura. Tradução de Jorge Eduardo Rivera. Santiago de Chile: Editorial Universitária, 1997, p.235. (Tradução nossa)
}

\section{intuitio}

\section{ISSN \\ Porto Alegre} 1983-4012

(1)

\section{Vol. $7-\mathrm{N}^{\mathrm{o}} .2$}

\begin{tabular}{|c|c|}
$\begin{array}{c}\text { Novembro } \\
2014\end{array}$ & p. $40-50$ \\
\hline
\end{tabular}


confrontação com outra postura nem dispensa um discurso e sua consequente argumentação. A verdade estaria relacionada à linguagem porque esta traz ao nosso entendimento informações sobre o ente ao qual se refere, dando-nos a entender que as sentenças cumprem a função de emitir a nós tudo o que existe como verdadeiro. Falar sobre algo é um comportamento que nós temos com os outros entes, nos fazendo acreditar que uma relação entre sujeito e objeto ${ }^{8}$ está em prioridade.

A primazia em afirmar ou negar algo no mundo, atribuída aos enunciados e pertencente a uma esfera lógica e semântica, é confrontada e questionada por Heidegger: ele busca uma fundamentação para a verdade, tarefa que não pertenceria mais às proposições e este é o tema que guia a parte inicial do parágrafo 44, uma vez que a justificação do conceito de verdade na tradição consistiria no acordo entre o enunciado e o ente que expressa.

A adequação seria efetivada a partir do momento em que a sentença pronuncia um ente que se ajusta às propriedades mostradas pela linguagem. Ente e sentença entram em conformidade, quer dizer, possuem a mesma perspectiva. A proposição é considerada verdadeira ao concretizar um conhecimento, pois este “deve 'dar' a coisa tal como ela é." " Essa concepção poderia nos remeter à relação entre a coisa real e o juízo dotado de um conteúdo ideal; ou fazer um retorno à relação sujeitoobjeto, caso fosse buscada uma conveniência entre o conhecimento de um sujeito e àquilo ao qual se refere, seja algo físico, vindo da consciência ou uma adequação entre dois entes.

A consequência mais grave se refere ao nosso julgamento, meio através do qual o conhecimento é posto em exercício. Em qualquer julgamento, o conteúdo avaliado é ideal, enquanto a coisa julgada é real e simplesmente dada. Essa indicação prévia do modo como nós conhecemos esclarece que a verdade fora determinada pela verificação ${ }^{10}$. Segundo esse método, próprio de um pensamento dominado pelas teorias empíricas e científicas, um enunciado só é verdadeiro mediante a constatação de que o ideal e o real estão em concordância, sem que qualquer outra informação seja adicionada ou sua interpretação seja modificada. Porém, o enunciado proposto não deve apontar para representações e sim, para as coisas mesmas.

\footnotetext{
${ }^{8}$ Sobre a crítica de Heidegger à relação sujeito-objeto, lê-se em Ser e Tempo que tal interpretação é tomada como "o ponto de partida 'evidente' para os problemas da teoria do conhecimento ou da 'metafísica do conhecimento'. Pois o que pode ser mais evidente que o fato de que um 'sujeito' se relaciona com um 'objeto' e vice-versa? Esta 'relação sujeito-objeto' se converte em um pressuposto necessário. Mas todo isso não passa de um pressuposto que - embora inquestionável em sua facticidade - resulta, sem embargo, e precisamente por isso, inteiramente fatal, se sua necessidade ontológica e, sobretudo, seu sentido ontológico permanecem obscuros." (Tradução nossa) (Cf. HEIDEGGER, M. Ser y Tiempo. Coleção: El saber y la Cultura. Tradução de Jorge Eduardo Rivera. Santiago de Chile: Editorial Universitária, 1997, p.85)

${ }^{9}$ HEIDEGGER, M. Ser y Tiempo. Coleção: El saber y la Cultura. Tradução de Jorge Eduardo Rivera. Santiago de Chile: Editorial Universitária, 1997, p.237. (Tradução nossa)

${ }^{10}$ Cf. HEIDEGGER, M. Ser y Tiempo. Coleção: El saber y la Cultura. Tradução de Jorge Eduardo Rivera. Santiago de Chile: Editorial Universitária, 1997, p.238: "Quando a verdade se faz fenomenalmente expressa no próprio conhecimento? Quando o conhecimento se revela como verdadeiro. A justificação de si mesmo dá ao conhecimento a segurança de estar na verdade. Por conseguinte, a relação de concordância se tornará visível dentro do contexto fenomênico da evidência." (Tradução nossa)
}

\begin{tabular}{|c|c|c|c|c|c|}
\hline intuitio & $\begin{array}{c}\text { ISSN } \\
1983-4012\end{array}$ & Porto Alegre & Vol.7- $\mathrm{N}^{\mathrm{o}} .2$ & $\begin{array}{c}\text { Novembro } \\
2014\end{array}$ & p. $40-50$ \\
\hline
\end{tabular}


Heidegger admite que a verificação precisa se direcionar ao próprio ente e que a formulação de enunciados não tem a função restrita de criar juízos ideais que concordem com as coisas reais. Conforme suas palavras:

[...] o que percebo é o mesmo ente ao qual o enunciado se refere. [...] Evidencia-se o caráter descobridor do enunciado. No processo de verificação o conhecimento permanece referido unicamente ao ente mesmo. É nele, por assim dizer, onde se lança a confirmação. $\mathrm{O}$ ente mesmo se mostra tal como ele é em si mesmo, quer dizer, que ele é conforme o que enunciado $o$ mostra e descobre. ${ }^{11}$

Ao defender que o enunciado deve se dirigir ao ente e não à sua representação, admitindo que a verificação traz este ente à descoberta, ele ressalta que a teoria da adequação é insuficiente. Em vez de pensar que um ente poderá concordar com outro ente ou com uma sentença, ele toma por base o ser-no-mundo, o qual, à época de Ser e Tempo, teria sido "o fundamento do fenômeno originário da verdade." 12 Pensar o desvelamento foi irremissível para levar adiante a tentativa de desvincular verdade e concordância.

Um de seus esforços consistiu na pergunta pela condição de possibilidade do conceito de verdade não se limitar às sentenças, opinião segundo a qual a proposição abriga uma verdade. Caberia ao logos o papel de dizer o que são as coisas, como os entes se comportam, o que há no mundo, enfim de deixar e fazer ver. Esse conceito foi desenvolvido no segundo parágrafo de Ser e Tempo, quando o filósofo delimitou o método fenomenológico da investigação, ao dizer: "O dizer, na medida em que é um dizer autêntico, o que é dito deve ser derivado daquilo de que se fala, de tal modo que a comunicação falante torne manifesto no dito, e acessível ao outro, aquilo sobre o que se fala."13

Se o enunciado mostra ou propõe uma coisa como aquilo que ela não é, será verdadeiro ou falso caso concorde ou não concorde com o objeto apreendido, respectivamente. Porém, na medida em que um enunciado traz algo para nossa visualização, apresenta a possibilidade de não permitir o seu desvelamento. Do mesmo modo que cada revelação envolve um ocultamento, a verdade engloba a não-verdade. Heidegger assume que o conceito de discurso, em seu sentido mais íntimo, possui a função de deixar e fazer ver, tirando aquilo sobre o que se fala do velamento. Mas o lugar da verdade não é a proposição; este equívoco surgira da explicação de que tudo o que se dá no enunciado e se apropria de uma descoberta também deixa e faz ver o ente retirado da ocultação, em seu mostrar-se.

A verdade não reside na proposição nem existe o critério da concordância, deslocando-se do enunciado para o Dasein, mas "como a abertura é o domínio do manifesto, do iluminado, também se poderá dizer que o Dasein está localizado na verdade" ${ }^{\Perp 14}$. É feita uma referência ao homem na condição

\footnotetext{
${ }^{11}$ HEIDEGGER, M. Ser y Tiempo. Coleção: El saber y la Cultura. Tradução de Jorge Eduardo Rivera. Santiago de Chile: Editorial Universitária, 1997, p.238. (Tradução nossa)

${ }^{12}$ HEIDEGGER, M. Ser y Tiempo. Coleção: El saber y la Cultura. Tradução de Jorge Eduardo Rivera. Santiago de Chile: Editorial Universitária, 1997, p.239. (Tradução nossa)

${ }^{13}$ HEIDEGGER, M. Ser y Tiempo. Coleção: El saber y la Cultura. Tradução de Jorge Eduardo Rivera. Santiago de Chile: Editorial Universitária, 1997, p.55. (Tradução nossa)

${ }^{14}$ NUNES, B. Passagem para o Poético. Filosofia e poesia em Heidegger. São Paulo: Edições Loyola, 2012, p.195.
} 
de ser-no-mundo, que descobre os entes intramundanos ou os retira do velamento no qual se encontram ${ }^{15}$. Essa inversão do lugar da verdade consiste em um ponto fundamental do parágrafo 44, a saber, seu tratamento existencial, onde o homem é sua condição de possibilidade.

Heidegger explicita essa relação com o exemplo das leis de Newton. Ficou determinado, quando Newton declarou suas leis, que ele as descobriu e posteriormente construiu uma verdade acerca dos acontecimentos próprios da natureza, que são independentes do homem. É como se as leis só tenham existido a partir do momento em que o físico as declarou, ignorando que tais fenômenos sempre estiveram em operação. Por isso, comumente associamos uma verdade a quem a observou, investigou e declarou como válida para todos.

Esse método foi adotado como prática comum na formulação de verdades científicas, designando cada pesquisador como o grande contribuinte da postulação da veracidade de uma teoria. A descoberta de Newton e dos demais estudiosos de quem temos notícias como declaradores de leis é antes um desvelamento, a retirada de uma verdade que já se sustentava de forma oculta e subentendida, mas que outras pessoas foram incapazes de perceber por falta de condições de pesquisa ou de um olhar mais atento. O método de verificação guiou as ciências, tendo sido, por consequência, adotado como critério de determinação da verdade nos diversos campos do saber.

$\mathrm{O}$ modo segundo o qual compreendemos a verificação recorre à relação sujeito-objeto ao se apoiar na opinião que o sujeito projeta no objeto, mesmo que este traga em si suas próprias características. Não seria possível haver qualquer verdade sem o Dasein e assim Heidegger assevera que "no modo de ser do Dasein, estamos 'na verdade'."16 Embora se encontre radicada no homem, foi necessário dissociá-la dos paradigmas da subjetividade para não pressupor verdades eternas ou negar a presença da tradição e da influência do mundo. Se não existisse uma referência a partir do homem, mas uma relação entre os entes simplesmente dados, como no caso de um enunciado em remissão a um objeto, seria impossível desvincular a verdade da concordância, visto que nosso próprio modo de conhecer exigiria a verificação.

O homem seria o ente capaz de retirar algo do velamento a partir do instante em que ele se depara com tudo o que lhe vem ao encontro dentro do mundo sem precisar ser a medida de todas as coisas. Ao mesmo tempo, Dasein é sempre um projeto (Entwurf) e, portanto, capaz de "projetar um horizonte, de projetar um pano de fundo sobre o qual algo pode ser dito verdadeiro ou falso." ${ }^{17} \mathrm{E}$ porque ele é abertura, é igualmente capaz de pressupor a verdade, o que significa compreender algo a partir do que ele mesmo é. Na condição de ser-no-mundo, não há um arbítrio que o coloque em uma

${ }^{15}$ Cf. HEIDEGGER, M. Ser y Tiempo. Coleção: El saber y la Cultura. Tradução de Jorge Eduardo Rivera. Santiago de Chile: Editorial Universitária, 1997, p.241: "Descobrir é um modo de ser do ser-no-mundo." (Tradução nossa)

${ }^{16}$ HEIDEGGER, M. Ser y Tiempo. Coleção: El saber y la Cultura. Tradução de Jorge Eduardo Rivera. Santiago de Chile: Editorial Universitária, 1997, p.247. (Tradução nossa)

${ }^{17}$ STEIN, E. Sobre a verdade. Lições preliminares ao parágrafo 44 de Ser e Tempo. Coleção filosofia. Ijuí: Unijuí, 2006, p.171. 
posição privilegiada, subjetiva e puramente absoluta ${ }^{18}$. Essa pressuposição ocorre independente da emissão de juízos porque o Dasein está em relação direta com a verdade.

\section{Verdade, não-verdade e desvelamento}

Ainda que Ser e Tempo não dispense o homem da questão aqui tratada, há uma mudança de posição: o Dasein é um projeto temporal e fático. Fala-se agora de um indivíduo que existe no mundo e é influenciado por acontecimentos históricos, impedindo a comprovação de fatos eternos e incontestáveis. O filósofo alemão apresenta a possibilidade da não-verdade, contudo, sem a intenção de destruir as atribuições de verdadeiro ou falso ${ }^{19}$ e sim, enquanto superação teórica de uma fundamentação da verdade nos enunciados. Se o homem é abertura e capaz de compreender o presente, os fatos ocorridos e suas projeções vindouras, ele não possui um total domínio da verdade, o que nos conduz ao pressuposto de que há algo que não se manifesta.

Enquanto o homem se dedica às suas atividades e ocupações, ele se depara com um limite que o impede de tirar todos os entes do encobrimento, já que o mistério permanece atuante e deixa sempre algo não revelado. Partindo da situação de ser-no-mundo, ele se projeta como medida diante do horizonte histórico no qual está inserido e, ao tomar qualquer posição, pode se deparar com o nãodesvelamento. Retirado do domínio de um saber absoluto, o homem se depara com a não-verdade, apresentada por Heidegger de dois modos: encobrimento (Verbergung) e errância (Irre).

A não-verdade significa encobrimento quando o ente permanece oculto em sua totalidade $\mathrm{e}$ quando o mistério, como um velamento originário, preserva essa dissimulação. Mesmo que o homem, ao persistir no caráter do ente que se manifesta, possa retirá-lo do velamento, sempre há um ocultamento total operando por trás da verdade. O mistério mais original consiste na verdade do Ser, que permanece não questionada em prol de um questionamento sobre os entes.

A intenção de Heidegger é nos conduzir ao domínio incógnito da verdade, o fundamento sobre o qual não são feitas conjeturas e que não é perguntado como um todo. Ao mesmo tempo em que se coloca como uma medida, o homem deve entender que a ele não é admitida uma certeza absoluta. Persistindo nessa postura e tentando manter-se como medida, ele sustenta os próprios erros, como se não permitisse a si mesmo enxergar o mundo e tomar suas decisões de acordo com um caráter historial, em vez de se prender com exclusividade aos acontecimentos de sua vida corrente. Se o Dasein vem a substituir o sujeito moderno, ele não se desvia da iminência do erro.

\footnotetext{
${ }^{18}$ Recorremos à interpretação de Ernildo Stein, para quem o horizonte de legitimação das verdades "não é mais uma ideia de um transcendental produzido solipsisticamente no interior de um sujeito transcendental. É, sim, algo que se nos apresenta como critério, como limite e é algo que faz com que saibamos administrar as nossas certezas e as nossas incertezas, dando-lhes algum tipo de critério ou garantia." (Cf. STEIN, E. Sobre a verdade. Lições preliminares ao parágrafo 44 de Ser e Tempo. Coleção filosofia. Ijuí: Unijuí, 2006, p.153)

${ }^{19}$ Cf. STEIN, E. Sobre a verdade. Lições preliminares ao parágrafo 44 de Ser e Tempo. Coleção filosofia. Ijuí: Unijuí, 2006, p.173: “[...] a chamada verdade fenomenológica que Heidegger sempre diz que é uma veritas transcendentalis não pretende conflitar com a discussão lógica da verdade ou falsidade como propriedades de proposições empíricas."
}

\begin{tabular}{|l|c|l|l|c|c} 
intuitio & ISSN & Porto Alegre & Vol.7- No. 2 & $\begin{array}{c}\text { Novembro } \\
2014\end{array}$ & p. 40-50 \\
\hline
\end{tabular}


Heidegger afirma que a errância permanece como um critério da verdade e faz parte da constituição humana do ser-aí enquanto um ente que tem a permissão de se enganar. Errar é parte constitutiva do fundamento da verdade e da abertura do Dasein, o campo da disputa entre o mistério que permanece inexplorado e a determinação de suas verdades históricas. Encontram-se, na errância, os diversos modos de engano cometidos pelo homem, dentre os quais podemos apontar a definição do erro conceitual, que significa o erro como não concordância entre sentença e objeto, assim como qualquer desvio acerca do conhecimento que temos de algo.

Somos levados a acreditar que a verdade é qualificada como o contrário do falso. Todavia, a falsidade não pode ser o oposto da verdade, uma vez que esta seria determinada como correção ou adequação. Mas o que é considerado falso pode ter outras interpretações que vão além da concordância. Uma obra de arte pode ser falsificada e, com isso, ser exposta a sua cópia em um museu, algo que não é a produção genuína de um artista. Uma declaração que não concorde com os fatos é chamada de errônea. E se alguém mentir diante de um tribunal deliberadamente, a falsidade maior não reside na incorreção do seu discurso, mas no fato de ter conhecimento do estado de coisas sobre as quais se fala e mesmo assim decidir enganar seus interlocutores, já que o réu tenha conhecimento sobre a verdadeira versão de sua história.

Nossa crença sobre a questão da falsidade está consolidada na concepção de que a verdade exprime o que é o verdadeiro como o real. Na conferência Sobre a essência da verdade (1943) nosso autor lança uma pergunta sobre o modo pelo qual entendemos tais conceitos, afirmando:

Assim falamos do ouro verdadeiro em distinção do falso. $\mathrm{O}$ ouro falso não é realmente como aparenta. Ele é apenas uma 'aparência' e por isso irreal. O irreal é considerado o oposto do real. Mas o ouro aparente é também algo real. Por isso dizemos mais obviamente: o ouro real é o ouro genuíno. Mas ambos são "reais" [...] A pergunta se torna de novo: o que significa aqui falso e verdadeiro ${ }^{20}$

Nesse contexto, o ouro autêntico seria aquele que concorda com todas as qualidades observadas, segundo as quais entendemos comumente o que seja o ouro na sua forma mais pura, enquanto o ouro falso é aquele que não concorda com a mesma referência, apenas se assemelha a esta. Porém, é preciso ressaltar que o acordo também ocorre entre o enunciado que proferimos e a coisa a qual nos referimos ${ }^{21}$. Tanto o consentimento entre sentença e coisa quanto entre a coisa $e$ as concepções prévias criadas em torno dela são determinantes do conceito tradicional de verdade, reforçando que "verdade é a adequação da coisa ao conhecimento."22

\footnotetext{
${ }^{20}$ HEIDEGGER, M. Vom Wesen der Wahrheit. Frankfurt am Main: Vittorio Klostermann, 1997, p.7. (Tradução nossa)

${ }^{21}$ Cf. HEIDEGGER, M. Vom Wesen der Wahrheit. Frankfurt am Main: Vittorio Klostermann, 1997, p.7: "Um enunciado é verdadeiro quando, o que ele significa ou diz, coincide com a coisa sobre a qual enuncia." (Tradução nossa)

${ }^{22}$ HEIDEGGER, M. Vom Wesen der Wahrheit. Frankfurt am Main: Vittorio Klostermann, 1997, p.8. (Tradução nossa)
}

\begin{tabular}{|l|c|l|l|l|l|}
\hline intuitio & $\begin{array}{c}\text { ISSN } \\
1983-4012\end{array}$ & Porto Alegre & Vol.7 $-\mathrm{N}^{\circ} .2$ & $\begin{array}{c}\text { Novembro } \\
2014\end{array}$ & p. 40-50 \\
\hline
\end{tabular}


Heidegger prefere o uso do termo desvelamento (Unverborgenheit). Primeiro, porque o desvelamento deixa subentendido que há algo encoberto. Segundo, o des-velamento - com ênfase no prefixo des - considera a verdade essencialmente conflitante e a ser conquistada na luta, na retirada brusca do ente do velamento. Terceiro, por este termo entende-se que há um jogo de opostos. Não se deve, contudo, retornar à falsidade como o conceito oposto à verdade. É preciso entender essa oposição como um co-pertencimento entre verdadeiro e não-verdadeiro, cuja disputa está sempre em latência. Como ele mesmo destacou na conferência A Origem da Obra de Arte (1935/36):

A verdade é não-verdade na medida em que lhe pertence o âmbito da proveniência do ainda-não-(do não-) revelado, no sentido do velamento. Ao mesmo tempo, no des-velamento como verdade vige o outro "não" de um duplo vedar. A verdade vige como tal na oposição de clareira e duplo velamento. A verdade é a disputa originário-inaugural na qual sempre de um certo modo se conquista o aberto, no qual, tudo, que como sendo se mostra e subtrai, se situa, e a partir do qual tudo se retrai. Quando e como esta disputa ecloda e aconteça, através dela os disputantes, clareira e velamento, caminham separados. Assim se conquista o aberto do espaço da disputa. A abertura deste aberto, isto é, a verdade, só pode ser o que ela é, ou seja, esta abertura, se ela e enquanto ela mesma, se dis-põe em seu aberto. ${ }^{23}$

Ao colocar verdade e não-verdade como dois polos complementares, Heidegger não quer ressaltar as características de veracidade e falsidade acerca dos enunciados. Então, podemos dizer que antes de ser uma mera oposição entre proposições ou uma concordância entre sujeito e objeto, o que existe é o conflito entre velamento e desvelamento. Ao investigar a essência da verdade, ele não demonstra preocupação em relacioná-la às experiências técnicas, científicas ou reflexivas, mas investigar a sua determinação como tal, procurando estabelecer sua instauração a partir de si mesma. A palavra aletheia significa a tentativa de uma recusa do velamento. Essa característica do ente em não estar encoberto retira uma referência necessária ao homem.

Mesmo porque não cabe ao homem conhecer e dominar tudo o que se dispõe. Sempre há algo diante dos entes, algo que os ilumina e os circunda, a saber: a clareira (Lichtung). O nome clareira ${ }^{24}$ designa um centro iluminado e livre entre os caminhos insinuantes e fechados da floresta. Um lugar aberto, através do qual o homem tem conexão com os entes, mas que não o permite acessá-los por inteiro, seja porque a aparência dos entes consegue nos iludir, seja porque o velamento acontece como uma camuflagem ou uma recusa natural da própria verdade de se deixar esclarecer. A verdade é o próprio desvelamento e não pertence às coisas ou aos enunciados ${ }^{25}$. Esta seria a sua essência: nunca

\footnotetext{
${ }^{23}$ HEIDEGGER, M. A Origem da Obra de Arte. Tradução de Idalina Azevedo da Silva e Manuel António de Castro. São Paulo: Edições 70, 2010, pp.153,155.

${ }^{24}$ Sobre o termo, diz Inwood que "Lichtung e lichten originam-se de Licht, 'luz', mas já perderam esta ligação, tendo passado a significar, em seu uso mais comum, 'clareira, senda' numa floresta, 'clarear' uma área. Heidegger retoma a sua associação com a luz, de modo que significam 'iluminação, iluminar'." (Cf. INWOOD, M. Dicionário Heidegger. Tradução de Luísa Buarque de Holanda. Rio de Janeiro: Jorge Zahar Editor, 2002, p.39)

${ }^{25}$ Cf. HEIDEGGER, M. A Origem da Obra de Arte. Tradução de Idalina Azevedo da Silva e Manuel António de Castro. São Paulo: Edições 70, 2010, pp.135,137: "O desvelamento (verdade) não é nem uma propriedade das coisas, no sentido do sendo, nem uma propriedade das proposições."
}

\begin{tabular}{|l|c|l|l|l|l|}
\hline intuitio & $\begin{array}{c}\text { ISSN } \\
1983-4012\end{array}$ & Porto Alegre & Vol.7- $\mathrm{N}^{\mathrm{o}} .2$ & $\begin{array}{c}\text { Novembro } \\
2014\end{array}$ & p. 40-50 \\
\hline
\end{tabular}


renunciar por completo ao seu acobertamento, em disputa originária (Urstreit) com a claridade do que se revela.

\section{Conclusão}

As explicações encontradas no parágrafo 44 são fundamentais. Não somente porque nele Heidegger apresenta uma nova visão sobre a verdade, mas também porque, ao pensar a estrutura da abertura do Dasein - condição humana de estar-aí - conferiu importância ao mundo. E segundo Ernildo Stein, é neste "aí onde se dá o velamento e o desvelamento, a partir de onde se coloca a questão da verdade."26 Essa observação se revela indispensável no projeto posterior de deslocar da ontologia para a estética o lugar do desvelamento da verdade, como ele apresenta em A Origem da Obra de Arte, onde o mundo entrará em confronto com a Terra. Ele articula a verdade com os elementos mundo e Terra, que estão em incessante combate ${ }^{27}$, com a intenção de nos levar a entender o acontecimento dessa disputa através da obra de arte.

Antes de ser concordância ou uma certeza indiscutível, a verdade se conquista no jogo antagônico entre manifesto e oculto. Heidegger escreve no texto Parmênides que "'Verdade' não é jamais, 'em si', apreensível por si, mas necessita ser ganha na luta. O desencobrimento é conseguido do encobrimento, em luta com ele." ${ }^{28} \mathrm{O}$ desdobramento da aletheia só é possível enquanto o ente estiver velado, para que então venha a ser desencoberto. Isso não acontece quando verdade é interpretada enquanto uma correção, já que qualquer exercício que busque priorizar a concordância acaba tomando a evidência como ponto de partida.

A clareira aponta para o desvelamento, mas ainda permite que a não-verdade esteja presente, retirando qualquer possibilidade de que existam respostas prontas e corretas a todos os nossos variados questionamentos. Se verdade e não-verdade fazem parte de um só domínio, é indispensável tratar a relação recorrendo ao desvelamento. Digamos que a verdade seja uma orientação da sentença ao objeto: não haveria aquele momento de descoberta - quer dizer, da retirada de algo que estava resguardado. Porém, existiria apenas um pálido consentimento baseado em uma comparação.

Quando Heidegger desvinculou o conceito de verdade de uma concordância entre enunciados e objetos, fazendo-a consistir na retirada de um ente do velamento, esse combate não poderia mais ser promovido pelo homem. A tensão seria efetivada na obra de arte, quer seja uma obra figurativa, arquitetônica ou poética. Temos agora um entendimento mais concreto da crítica projetada por Heidegger, que nos oferece uma leitura fértil e ampla acerca de um conceito ao qual nos dirigimos

\footnotetext{
${ }^{26}$ STEIN, E. Sobre a verdade. Lições preliminares ao parágrafo 44 de Ser e Tempo. Coleção filosofia. Ijuí: Unijuí, 2006, p.23.

${ }^{27} \mathrm{O}$ jogo de mostrar e ocultar é conquistado através de um Mundo e da Terra. Ainda que se trate de uma relação conflituosa, é preciso pensar os dois elementos em uma relação de co-pertença.

${ }^{28}$ HEIDEGGER, M. Parmênides. Tradução de Sérgio Mário Wrublevski. Petrópolis: Vozes; Bragança Paulista: Editora Universitária São Francisco, 2008, p.35.
}

\begin{tabular}{|l|c|l|l|l|l} 
intuitio & $\begin{array}{c}\text { ISSN } \\
1983-4012\end{array}$ & Porto Alegre & Vol.7 $-\mathrm{N}^{\circ} .2$ & $\begin{array}{c}\text { Novembro } \\
2014\end{array}$ & p. 40-50 \\
\hline
\end{tabular}


continuamente. Este é um dos principais empreendimentos que permeiam não somente o pensamento heideggeriano, mas nossas próprias tentativas de lidar com tudo aquilo que pertence ao nosso mundo circundante. A verdade é, de certo modo, nosso objetivo e principal desafio mediante toda e qualquer tentativa de lidar com as ciências, a arte e a filosofia.

\section{Referências}

GIACOIA JUNIOR, O. Heidegger Urgente. Introdução a um Novo Pensar. $1^{\text {a }}$ edição. São Paulo: Três Estrelas, 2013.

HEIDEGGER, M. A Origem da Obra de Arte. Tradução de Idalina Azevedo da Silva e Manuel António de Castro. São Paulo: Edições 70, 2010.

Aletheia (Heráclito, fragmento 16). In: Ensaios e Conferências. Coleção Pensamento Humano. $7^{\mathrm{a}}$ edição. Tradução de Márcia Sá Cavalcante Schuback. Petrópolis: Vozes; Bragança Paulista: Editora Universitária São Francisco, 2006. . Meditação. Tradução de Marco Antônio Casanova. Petrópolis: Vozes, 2010. . Parmênides. Tradução de Sérgio Mário Wrublevski. Petrópolis: Vozes; Bragança Paulista: Editora Universitária São Francisco, 2008.

. Sein und Zeit. Tübingen: Max Niemeyer Verlag, 2006.

Ser e Tempo. Coleção Pensamento Humano. $16^{\mathrm{a}}$ edição. Tradução de Márcia Sá Cavalcante Schuback. Petrópolis: Vozes, 2006.

. Ser y Tiempo. Coleção: El saber y la Cultura. Tradução de Jorge Eduardo Rivera. Santiago de Chile: Editorial Universitária, 1997. Brasileiro, 1995.

Sobre o humanismo. Tradução de Emmanuel Carneiro Leão. $2^{\mathrm{a}}$ edição. Rio de Janeiro: Tempo Vom Wesen der Wahrheit. Frankfurt am Main: Vittorio Klostermann, 1997.

INWOOD, M. Dicionário Heidegger. Tradução de Luísa Buarque de Holanda. Rio de Janeiro: Jorge Zahar Editor, 2002.

NUNES, B. Passagem para o Poético. Filosofia e poesia em Heidegger. São Paulo: Edições Loyola, 2012.

STEIN, E. Pensar e Errar. Um ajuste com Heidegger. Ijuí: Unijuí, 2011.

Seis estudos sobre "Ser e Tempo". $3^{\mathrm{a}}$ edição. Petrópolis: Vozes, 2006.

2006.

Sobre a verdade. Lições preliminares ao parágrafo 44 de Ser e Tempo. Coleção filosofia. Ijuí: Unijuí,

TUGENDHAT, E. Der Wahrheitsbegriff bei Husserl und Heidegger. Berlin: Walter de Gruyter \& Co: 1967.

Lições Introdutórias à Filosofia Analítica da Linguagem. Tradução de Ronai Pires da Rocha. Ijuí: Editora Unijuí, 2006.

Recebido em: 31/05/2014

Aprovado para publicação em: 06/08/2014 